\title{
NAVIGATION IN TOTAL KNEE ARTHROPLASTY
}

\section{ABSTRACT}

Navigation was the most significant advance in instrumentation for total knee arthroplasty over the last decade. It provides surgeons with a precision tool for carrying out surgery, with the possibility of intraoperative simulation and objective control over various anatomical and surgical parameters and references. Since the first systems, which were basically used to control the alignment of bone cutting referenced to the mechanical axis of the lower limb, many other surgical steps have been incorporated, such as component rotation, ligament balancing and arranging the symmetry of flexion and extension spaces, among others. Its efficacy as a precision tool with an effective capacity for promoting better alignment of the lower-limb axis has been widely proven in the literature, but the real value of optimized alignment and the impact of navigation on clinical results and the longevity of arthroplasty have yet to be established.

Keywords - Knee; Arthroplasty; Navigation; ComputerAssisted Surgery

\section{INTRODUCTION}

Knee arthroplasty has been indicated with growing frequency, especially over the last decade. Its success depends on various factors, such as component design, the quality of the material used to make the component, the manufacturing process, adequate patient selection and the surgical technique. Most of these are developed by the surgical material and implant industry, and the evolution of the industry has enabled great advances in the quality of the prostheses available. On the other hand, with regard to surgical technique, surgeons are the primary factor and evolution of concepts and surgical strategy are the main factors for advances. The industry has contributed towards development of surgical instruments and tools that have the aim of assisting in and improving the accomplishment of operations by surgeons. Within this field, the most significant advance over the past decade has been the emergence of navigation systems for knee arthroplasty.

Computer Assisted Orthopedic Surgery (CAOS) is a field of technological evolution that has been developing particularly over the last 10 years, and a variety of surgical applications have emerged over this period. These include workstations for preoperative planning and simulation and robotics for use in carrying out surgical procedures, and among these, navigation systems.

The basic precepts of knee arthroplasty include reestablishment of the alignment of the lower limb and maintenance or recovery of joint stability. Navigation systems provide guidance and they measure various intraoperative parameters that help surgeons to reach these objectives.

\section{NAVIGATION SYSTEMS}

Navigation systems take the special positions of patients' anatomical reference points and surgical instruments are transferred to a computer and processed using software that is capable of providing surgeons with information relating to various steps of the operation in a visual or graphical and numerical form, the-

Attending physician in the Knee Group, Institute of Orthopedics and Traumatology, HC/FMUSP.

Work performed at the Institute of Orthopedics and Traumatology

Correspondence: Rua Dr. Ovídio Pires de Campos 333, 3º Andar, Cerqueira Cesar, 05403-010 São Paulo, SP. Email: rmotaa@uol.com.br

Work received for publication: October 12, 2010; accepted for publication: November 14, 2010.

The authors declare that they did not have any conflict of interests in producing this article 
reby giving surgeons a greater degree of control and precision in carrying out the procedure. One example in arthroplasty is in relation to the positioning of a cutting guide, in which the navigation system provides the surgeon with information on the special orientation of the resultant cut (varus/valgus, antecurvatum/recurvatum), with great precision (Figure 1), thus allowing the necessary adjustments to be made, in order to obtain a position that the surgeon considers ideal. Hence, these are systems that are capable of helping surgeons to carry out various stages of the operation with greater precision and safety, and also for enabling decision-making and adjustments to the surgical plan according to the data obtained during the operation through the navigation system.

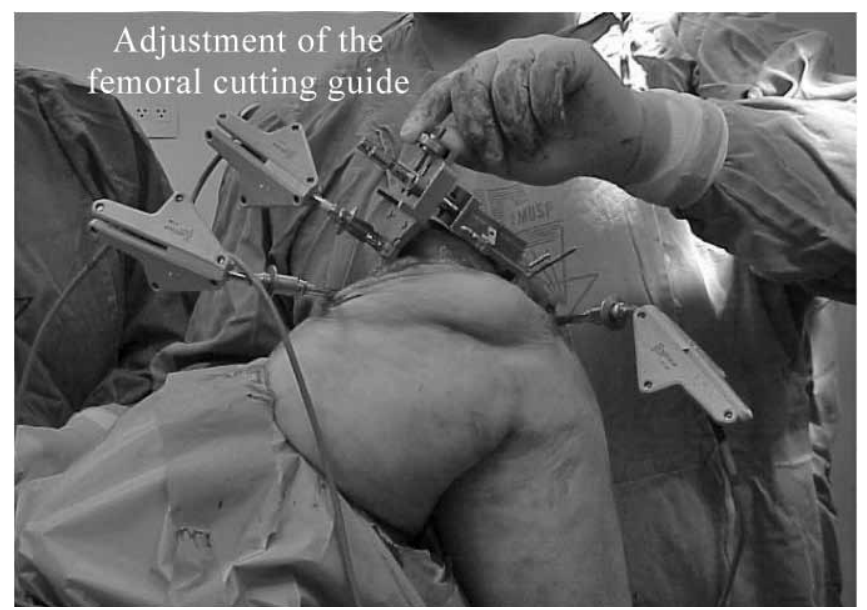

Figure 1 - Navigation for distal cut on femur. Rigid bodies with infrared transmitters coupled to the femur, tibia and femoral cutting guide.

These systems may be based on images acquired preoperatively or intraoperatively, or may be independent of images. In image-based systems, the software works with images acquired previously using CT or MRI, or intraoperatively using fluoroscopy (mostly used for fractures). The images need to be coupled with the patient's real spatial position on the surgical table. For this, it is necessary to furnish the system with one or more real anatomical reference points. From this, the system can then discern the surgical field and the parameters programmed by the system. In image-free navigation, the system is fed only with anatomical reference points acquired during the surgical procedure, in which some regions and reference points are digitized (Figure 2). The method most used for transmitting information to the system uses infrared signals. These systems may

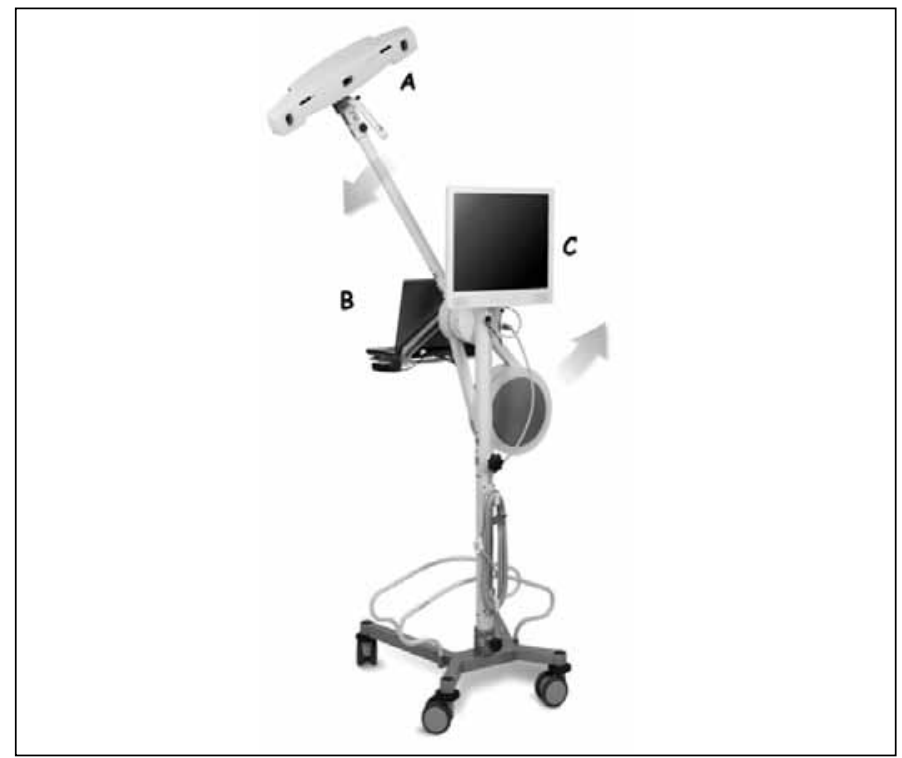

Figure 2 - Navigator with (A) optical tracking camera, (B) computer and $(\mathrm{C})$ monitor.

be active or passive, according to the infrared generation method (IV). In both configurations, navigations systems are composed of a computer with the specific software and an optical tracking camera (Figure 2). The surgical guides have adaptations to receive rigid bodies containing infrared transmitting diodes in active systems, or reflective spheres in passive systems. The latter also require an external infrared source coupled to the optical tracking camera. There are also transmitters coupled to the patient, which are held on the bone using threaded pins. A pointer/palpator with which the various anatomical references are transmitted to the navigation system is also needed (Figure 3). Infrared navigation requires direct viewing, without interference between the optical tracking camera and the transmitters. Thus, the surgical team should be positioned such that they do not obstruct the signal. One alternative that is being studied is electromagnetic navigation, which does not suffer from "visual" interference, but requires special instruments and materials that do not generate electromagnetic fields, thereby raising the cost of the system.

The first navigation systems for total knee arthroplasty aimed to control the alignment and thickness of the proximal tibial and distal femoral bone cuts, so as to obtain correct limb alignment. Today, several other parameters have been incorporated by different systems, such as the size and rotational alignment of the components, the ligament balance, equalization of the flexion and extension spaces, and alignment of the extensor apparatus ${ }^{(1-7)}$. Another interesting development 


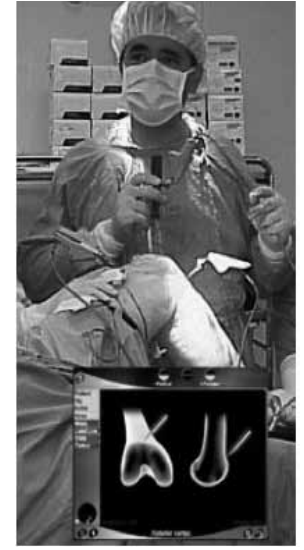

Figure 3 - Surgeon inputting to the system the anatomical reference point indicated on the monitor, using a pointer coupled to a rigid body.

is the possibility of conducting intraoperative planning and simulation ${ }^{(1,4,8)}$. In this, after carrying out a stage such as making a tibial cut, for example, a variety of size options for the polyethylene and the femoral component can be simulated, and likewise for the femoral cut. The thickness, varus and valgus tilt, flexion and extension, and rotation in relation to various parameters such as the epicondylar axis or posterior alignment of the femoral condyles can be varied, and the effect of the options and changes can be seen in relation to the limb alignment, ligament tension and balance between the flexion and extension spaces (Figure 4).

The navigation system used for total knee arthroplasty is therefore a precision instrument for carrying out the operation, and it also has the potential for aiding the surgeon making intraoperative decisions, through the resource of simulating actions before implementing them. It has also been shown to be a good teaching tool, given that the effect of each action performed during the operation can be seen immediately. This does not mean that the navigator does away with the need for the surgeon's skills or diminishes the value of his experience, since the navigator does not point out the path to follow or make the surgeon's decisions for him, but only helps him to obtain and measure the result planned for each action. Thus, on the contrary, the navigator adds power to the surgeon's knowledge and experience through providing him with precise and objective parameters in real time during the operation.

Conditions that impose difficulty in using conventional anatomical reference points for positioning cutting guides, such as the presence of synthesis material obstructing the access to the medullary canal, and/or conditions that imply that the ligament balance is more complex, such as in cases of major deformity inside or

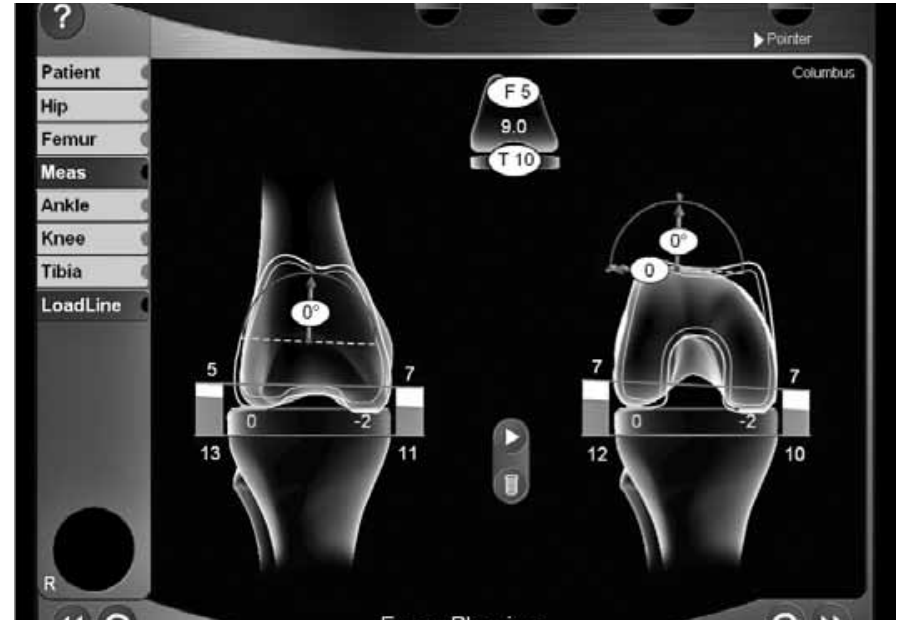

Figure 4 - Screen simulating the femoral cut after carrying out the tibial cut. All the variables (sizes of femur and insert, rotation and height of the femoral cut) can be modified and their effect on the lateral and medial flexion and extension spaces can be observed.

outside the joint (Figure 5), or in patients with previous surgery such as osteotomy, make the use of the navigator more significant. Under such conditions, the discernment capacity of the navigator remains unaffected, and the system continues to supply precise parameters to the surgeon ${ }^{(9-11)}$. Likewise, another situation in which navigation has great potential for application is in minimally invasive arthroplasty, in which the reduced direct viewing of the surgical field can be compensated by the virtual reference provided by the navigator ${ }^{(9-14)}$.

Documentation is another resource offered by the navigation system. It registers a variety of data acquired during the operation, thus creating a file containing the patient's pre and postoperative conditions, along with data relating to the different steps within
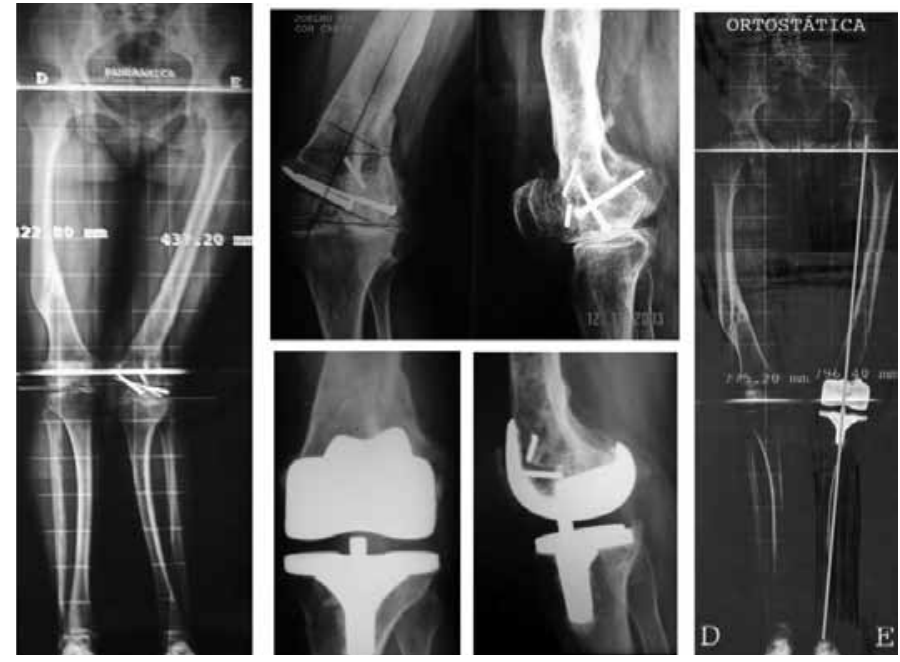

Figure 5 - Complex tibial and femoral deformity: before and after navigated arthroplasty. 
the operation, with the orientation of each bone cut (Figure 6). Through this, it is possible to generate reports and construct databases for clinical and scientific documentation.

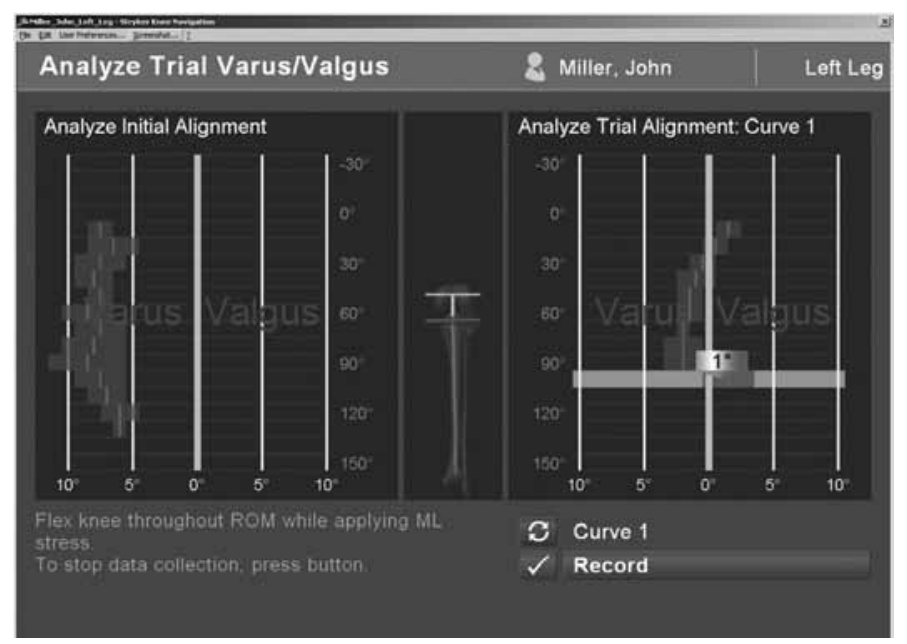

Figure 6 - Navigation screen comparing the limb alignment relative to the mechanical axis, along the entire arc of movement. On the left, the initial situation; and on the right, after making cuts and placing the test implants, still with the possibility of adjustment.

Complications and disadvantages relating to the use of navigation systems have also been described. Feeding the system through palpation of the anatomical reference points and carrying out dynamic maneuvers is time-consuming. Even though some authors, such as Stiehl et $\mathrm{al}^{(15)}$, have demonstrated the possibility of reducing the duration of the operation, most authors have reported that the duration of the operation increases by around 10 to 15 minutes. There have also been some reports of cases of fracture at the pin fixation sites in the tibia and femur ${ }^{(16-19)}$. However, these are isolated reports, and there is no evidence that the incidence of periprosthetic fractures is greater than in non-navigated arthroplasty.

The impact of using navigators for total knee arthroplasty has yet to be proven. Although there are many studies in the literature with good levels of evidence proving that navigation-assisted surgery has greater precision for obtaining the desired alignment for the lower limb ${ }^{(8,20-31)}$, it is still not possible to demonstrate gains in the clinical results or in the longevity of implants, despite some favorable studies ${ }^{(12,14,25,26,32-40)}$. Although there is some controversy, there is evidenced of possible parallel benefits relating to a lower

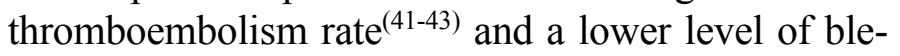
eding $^{(11,44-47)}$ with navigation. The initial experiences from using navigation systems for knee arthroplasty have now reached around 10 years in length, which is still not enough for durability studies. The systems available on the market are not homogenous and have been evolving rapidly and incorporating new parameters. It is difficult to assess the importance of each of these parameters. However, it is perhaps more important to define what is really significant for the success of arthroplasty. Today, the concept of neutral alignment of the lower limb in relation to the mechanical axis predominates as the standard to be attained, but other parameters are controversial and difficult to determine. For example, what is the ideal rotation of the femoral component, and how should this be determined? Is the ideal the epicondylar axis, the Whiteside line or the plane of the tibial cut? Is there an overall formula, the same for all patients, or should there be a personalized solution for each case? It is certain that navigation systems cannot answer all these questions, but they may help in finding the answers through intraoperative measurements on a variety of parameters, thereby enabling greater objectivity in studying the different options that are faced in arthroplasty. Perhaps one of the most positive aspects of the advent of navigation in arthroplasty has been that these very basic issues have been brought into the discussion. These issues had perhaps remained in the background because of the great attention given to the evolution of implants and materials.

\section{FINAL REMARKS}

Within our setting, the use of navigation systems for total knee arthroplasty is an accessible option in many regions of Brazil. Although their use is still limited, it has been increasing. These systems should be regarded as a tool that is at surgeons' disposal, which adds power to their knowledge, and never as an intelligent or autonomous system that might compensate for possible deficiencies or limited experience among surgeons. As with all new technologies, there are difficulties relating to availability, costs and resistance from payment sources. There is even resistance among surgeons, who view the systems with caution, mistrust or even disbelief. Time, results, evolution of navigation systems and cost reductions, among other factors, will determine in the future what role and space will be reserved for navigation systems for knee arthroplasty, just as for other applications. 


\section{REFERENCES}

1. Hakki S, Coleman S, Saleh K, Bilotta VJ, Hakki A. Navigational predictors in determining the necessity for collateral ligament release in total knee replacement. J Bone Joint Surg Br. 2009;91(9):1178-82.

2. Koulalis D, O'Loughlin PF, Plaskos C, Kendoff D, Pearle AD. Adjustable cutting blocks for computer-navigated total knee arthroplasty a cadaver study. J Arthroplasty. 2010;25(5):807-11.

3. Luring C, Oczipka F, Grifka J, Perlick L. The computer-assisted sequential lateral soft-tissue release in total knee arthroplasty for valgus knees. Int Orthop. 2008;32(2):229-35

4. Moon YW, Seo JG, Lim SJ, Yang JH. Variability in femoral component rotation reference axes measured during navigation-assisted total knee arthroplasty using gap technique. J Arthroplasty. 2010;25(2):238-43.

5. Mullaji A, Shetty GM. Computer-assisted TKA: greater precision, doubtful clinical efficacy: opposes. Orthopedics. 2009;32(9). Disponível em: http://www. orthosupersite.com/view.aspx?rid=42846

6. Mullaji AB, Shetty GM. Lateral epicondylar osteotomy using computer navigation in total knee arthroplasty for rigid valgus deformities. J Arthroplasty. 2010;25(1):166-9.

7. Picard F, Deakin AH, Clarke IV, Dillon JM, Kinninmonth AW. A quantitative method of effective soft tissue management for varus knees in total knee replacement surgery using navigational techniques. Proc Inst Mech Eng $\mathrm{H}$. 2007;221(7):763-72

8. Magin MN. Computer-assisted total knee replacement (TKR) using Orthopilot navigation system. Oper Orthop Traumatol. 2010;22(1):63-80.

9. Biasca N, Schneider TO, Bungartz M. Minimally invasive computer-navigated total knee arthroplasty. Orthop Clin North Am. 2009;40(4):537-63.

10. Kim KI, Ramteke AA, Bae DK. Navigation-assisted minimal invasive total knee arthroplasty in patients with extra-articular femoral deformity. J Arthroplasty. 2010;25(4):658.e17-22

11. Millar NL, Deakin AH, Millar LL, Kinnimonth AW, Picard F. Blood loss following total knee replacement in the morbidly obese: Effects of computer navigation. Knee. 2010 Jun 28. [Epub ahead of print]

12. Lüring C, Beckmann J, Haiböck P, Perlick L, Grifka J, Tingart M. Minimal invasive and computer assisted total knee replacement compared with the conventional technique: a prospective, randomised trial. Knee Surg Sports Traumatol Arthrosc. 2008;16(10):928-34.

13. Pagnano MW, Argenson JN, Parratte S, Scuderi GR, Booth RE Jr. Minimally invasive total knee arthroplasty meets computer navigation. J Bone Joint Surg Am. 2009;91(Suppl 5):56-8.

14. Seon JK, Song EK, Yoon TR, Park SJ, Bae BH, Cho SG. Comparison of functional results with navigation-assisted minimally invasive and conventional techniques in bilateral total knee arthroplasty. Comput Aided Surg. 2007;12(3):189-93.

15. Stiehl JB, Jackson S, Szabo A. Multi-factorial analysis of time efficiency in total knee arthroplasty. Comput Aided Surg. 2009;14(1-3):58-62

16. Beldame J, Boisrenoult $P$, Beaufils $P$. Pin track induced fractures around computer-assisted TKA. Orthop Traumatol Surg Res. 2010;96(3):249-55.

17. Bonutti $P$, Dethmers $D$, Stiehl JB. Case report : femoral shaft fracture resulting from femoral tracker placement in navigated TKA. Clin Orthop Relat Res. 2008;466(6):1499-502.

18. Hoke D, Jafari SM, Orozco F, Ong A. Tibial Shaft Stress Fractures Resultingfrom Placement of Navigation Tracker Pins. J Arthroplasty. 2010 Jul 19. [Epub ahead of print]

19. Li CH, Chen TH, Su YP, Shao PC, Lee KS, Chen WM. Periprosthetic femoral supracondylar fracture after total knee arthroplasty with navigation system. J Arthroplasty. 2008;23(2):304-7.

20. Bäthis H, Shafizadeh S, Paffrath T, Simanski C, Grifka J, Lüring C. Are computer assisted total knee replacements more accurately placed? A meta-analysis of comparative studies. Orthopade. 2006;35(10):1056-65.

21. Bauwens K, Matthes G, Wich M, Gebhard F, Hanson B, Ekkernkamp A, et al. Navigated total knee replacement. A meta-analysis. J Bone Joint Surg Am. 2007;89(2):261-9.

22. Biant LC, Yeoh K, Walker PM, Bruce WJ, Walsh WR. The accuracy of bone resections made during computer navigated total knee replacement. Do we resect what the computer plans we resect? Knee. 2008;15(3):238-41.

23. Dattani R, Patnaik S, Kantak A, Tselentakis G. Navigation knee replacement. Int Orthop. 2009;33(1):7-10.

24. Dorr LD, Deshmane P. Precision surgery. Orthopedics. 2009;32(9). Disponível em: http://www.orthosupersite.com/view.aspx?rid=42846
25. Dutton AQ, Yeo SJ, Yang KY, Lo NN, Chia KU, Chong HC. Computer-assisted minimally invasive total knee arthroplasty compared with standard total knee arthroplasty. A prospective, randomized study. J Bone Joint Surg Am. 2008;90(1):2-9.

26. Ensini A, Catani F, Leardini A, Romagnoli M, Giannini S. Alignments and clinical results in conventional and navigated total knee arthroplasty. Clin Orthop Relat Res. 2007;(457):156-62.

27. Hauschild O, Konstantinidis L, Strohm PC, Niemeyer P, Suedkamp NP, Helwig P. Reliability of leg alignment using the OrthoPilot system depends on knee position: a cadaveric study. Knee Surg Sports Traumatol Arthrosc. 2009;17(10):1143-51.

28. Jenny JY, Miehlke RK, Giurea A. Learning curve in navigated total knee replacement. A multi-centre study comparing experienced and beginner centres. Knee. 2008;15(2):80-4.

29. Koyonos L, Stulberg SD, Moen TC, Bart G, Granieri M. Sources of error in total knee arthroplasty. Orthopedics. 2009;32(5):317.

30. Manzotti A, Cerveri P, De Momi E, Pullen C, Confalonieri N. Relationship between cutting errors and learning curve in computer-assisted total knee replacement. Int Orthop. 2010;34(5):655-62.

31. Zigo P, Ranke TP, Ziegenbalg A, Pfeiffer S. Axial deviation in total knee arthroplasty-is the navigation system necessary? Bratisl Lek Listy. 2009;110(6):340-4.

32. Bertsch C, Holz U, Konrad G, Vakili A, Oberst M. Early clinical outcome after navigated total knee arthroplasty. Comparison with conventional implantation in TKA: a controlled and prospective analysis. Orthopade. 2007;36(8):739-45.

33. Browne JA, Cook C, Hofmann AA, Bolognesi MP. Postoperative morbidity and mortality following total knee arthroplasty with computer navigation. Knee. 2010;17(2):152-6.

34. Kamat YD, Aurakzai KM, Adhikari AR, Matthews D, Kalairajah Y, Field RE. Does computer navigation in total knee arthroplasty improve patient outcome at midterm follow-up? Int Orthop. 2009;33(6):1567-70.

35. Matsumoto T, Tsumura N, Kurosaka M, Muratsu H, Yoshiya S, Kuroda R. Clinical values in computer-assisted total knee arthroplasty. Orthopedics. 2006;29(12):1115-20.

36. Molfetta L, Caldo D. Computer navigation versus conventional implantation for varus knee total arthroplasty: a case-control study at 5 years follow-up. Knee. 2008;15(2):75-9

37. Pang $\mathrm{CH}$, Chan WL, Yen $\mathrm{CH}$, Cheng SC, Woo SB, Choi ST, et al. Comparison of total knee arthroplasty using computer-assisted navigation versus conventional guiding systems: a prospective study. J Orthop Surg (Hong Kong). 2009;17(2):170-3.

38. Seon JK, Park SJ, Lee KB, Li G, Kozanek M, Song EK. Functional comparison of total knee arthroplasty performed with and without a navigation system. Int Orthop. 2009;33(4):987-90.

39. Song EK, Seon JK, Yoon TR, Park SJ, Cho SG, Yim JH. Comparative study of stability after total knee arthroplasties between navigation system and conventional techniques. J Arthroplasty. 2007;22(8):1107-11.

40. Spencer JM, Chauhan SK, Sloan K, Taylor A, Beaver RJ. Computer navigation versus conventional total knee replacement: no difference in functional results at two years. J Bone Joint Surg Br. 2007;89(4):477-80.

41. Kalairajah Y, Cossey AJ, Verrall GM, Ludbrook G, Spriggins AJ. Are systemic emboli reduced in computer-assisted knee surgery?: A prospective, randomised, clinical trial. J Bone Joint Surg Br. 2006;88(2):198-202.

42. Kim YH, Kim JS, Hong KS, Kim YJ, Kim JH. Prevalence of fat embolism after total knee arthroplasty performed with or without computer navigation. J Bone Joint Surg Am. 2008;90(1):123-8.

43. Ooi LH, Lo NN, Yeo SJ, Ong BC, Ding ZP, Lefi A. Does computer-assisted surgical navigation total knee arthroplasty reduce venous thromboembolism compared with conventional total knee arthroplasty? Singapore Med J. 2008;49(8):610-4.

44. Chang CW, Wu PT, Yang CY. Blood loss after minimally invasive total knee arthroplasty: effects of imageless navigation. Kaohsiung J Med Sci. 2010;26(5):23743.

45. Kalairajah Y, Simpson D, Cossey AJ, Verrall GM, Spriggins AJ. Blood loss after total knee replacement: effects of computer-assisted surgery. J Bone Joint Surg Br. 2005;87(11):1480-2.

46. Schnurr C, Csécsei G, Eysel P, König DP. The effect of computer navigation on blood loss and transfusion rate in TKA. Orthopedics. 2010;33(7):474

47. Thiengwittayaporn S, Junsee D, Tanavalee A. A comparison of blood loss in minimally invasive surgery with and without electromagnetic computer navigation in total knee arthroplasty. J Med Assoc Thai. 2009;92(Suppl 6):S27-32. 